\title{
In-situ Synchrotron Radiation X-Ray Diffraction Study of Crystallization Kinetics of Polymorphs of 1,3-dioleoyl-2-palmitoyl glycerol (OPO)
}

\author{
Laura Bayés-García*, a Teresa Calvet, ${ }^{a}$ Miquel Àngel Cuevas-Diarte, ${ }^{a}$ Satoru Ueno, ${ }^{b}$ and Kiyotaka Sato ${ }^{b}$ \\ Received (in $X X X, X X X)$ Xth $X X X X X X X X X 200 X$, Accepted Xth $X X X X X X X X X 200 X$ \\ First published on the web Xth $X X X X X X X X X 200 X$ \\ DOI: 10.1039/b000000x
}

\begin{abstract}
We examined the influence of kinetics on the polymorphic behavior of 1,3-dioleoyl-2-palmitoyl glycerol (OPO), a triacylglycerol (TAG) present in natural oils such as olive oil and human breast milk. Pure OPO was heated at

${ }_{10} 15^{\circ} \mathrm{C} \cdot \mathrm{min}^{-1}$ in all cases. The polymorphic crystallization of OPO was studied at different cooling rates $\left(15^{\circ}, 2^{\circ}, 1^{\circ}\right.$, and $\left.0.5^{\circ} \mathrm{C} \cdot \mathrm{min}^{-1}\right)$, and the dynamic polymorphic transformations were characterized on heating by simultaneously using Differential Scanning Calorimetry (DSC) and Synchrotron Radiation X-Ray Diffraction (SR-XRD) with smallangle X-ray diffraction (SAXD) and wide-angle X-ray diffraction (WAXD). Thermo-optical Microscopy (TOM) was also used in order to observe the polymorphic transitions. Polymorphic forms of OPO were identified and

15 characterized. As the cooling rate decreased, more stable forms crystallized, not following the Ostwald step rule, although in most cases concurrent crystallization occurred and the whole process was highly complex.
\end{abstract}

\section{Introduction}

Many crystals exhibit polymorphism, in which structural determination and thermodynamic stabilization of the 20 polymorphic modifications are of primary significance to determining the overall polymorphic nature of every substance. $^{1}$ In addition, the kinetic properties of crystallization and structural transformation are important, particularly for the application of polymorphic crystal systems 25 in pharmaceutical, biomedical, food technology, and other applications $^{2}$. As for the crystallization of different polymorphic forms, the Ostwald step rule ${ }^{3-6}$ has been used for macroscopic estimation of the behavior of multiple polymorphic forms when they are crystallized from vapor, 30 solution, and melt phases. This rule dictates that less stable polymorphic forms crystallize much faster than more stable forms when the driving force for crystallization takes place under certain values of supersaturation and supercooling and less stables forms transform to more stable forms after the 35 crystallization. Actually, the kinetics of polymorphic nucleation of various systems often follows this rule. For example, a metastable vaterite form crystallizes faster than the more stable calcite in $\mathrm{CaCO}_{3}{ }^{7,} 8$ However, more detailed studies are needed to examine the effects of supercooling, 40 additives, etc. and becomes necessary to establish some rules of behavior of the influence of kinetics on the polymorphic crystallization and study the situations where the Ostwald step rule may be complemented.

Triacylglycerols (TAGs) are the main components of 45 alimentary fats and oils. Fat structures and compositions determine their physical properties, 10 (e.g., rheology, morphology, and texture), where polymorphism exerts a strong influence. Many studies have focused on the polymorphism of pure TAGs and binary mixtures ${ }^{11-16}$ and the 50 influence of kinetics on polymorphic behavior. ${ }^{17-21}$ The kinetics of fat crystallization is important to produce the desired product characteristics. Chong et al. ${ }^{22}$ studied the influence of very low cooling rates on the crude palm oil crystallization in order to understand effects of cooling rates 55 on its fractionation. Roelands et al. ${ }^{23}$ compared theoretical and experimentally determined nucleation rates in the precipitation processes of ionic and molecular compounds, and developed a standard procedure to measure them. Referring to isothermal crystallization kinetics, Foubert et ${ }_{60} \mathrm{al}^{24}$ describes a stop-and-return DSC method used in fat samples, which consists of stopping the crystallization at different moments during the isothermal crystallization and raising the temperature of the sample. However, Marangoni et al. ${ }^{25}$ focused on nonisothermal nucleation of TAGs and ${ }_{65}$ developed a model to estimate activation energy for nucleation in palm oil, milk fat, and other palm oil-based fats, defining the new parameter of supercooling-time exposure. Bouzidi et al. ${ }^{26}$ used a model-free analysis of the kinetics of liquid-solid transformations for TAGs, and demonstrated the 70 existence of critical rates of cooling and specific growth modes. Moreover, Lam et al. ${ }^{27}$ analyzed the influence of cooling rate on the formation of self-assembled fibrillar networks of 12 hydroxystearic acid (12HSA).

The present study analyzes a TAG (1,3-dioleoyl-2-palmitoyl 75 glycerol, OPO) that is important in palm oil fractionation, ${ }^{28-30}$ as it belongs to low-melting temperature fractions. Palm oil is often modified to improve its applicability as an edible oil. Due to its heterogeneous composition, well-defined fractions with a high added value are obtained through fractionation. ${ }_{80}$ Basically, dry fractionation consists of separating successively different crystal fractions obtained by controlled cooling from the melt. As the temperature decreases during fractionation, fractions richer in high levels of monounsaturated TAGs are separated. Minato et al. ${ }^{12}$ studied the thermodynamic and 85 polymorphic behavior of OPO and 1,3-dipalmitoyl-2-oleoyl glycerol (POP) and their binary mixtures, showing the occurrence of $\alpha, \beta$, and two $\beta$ forms of OPO. However, 


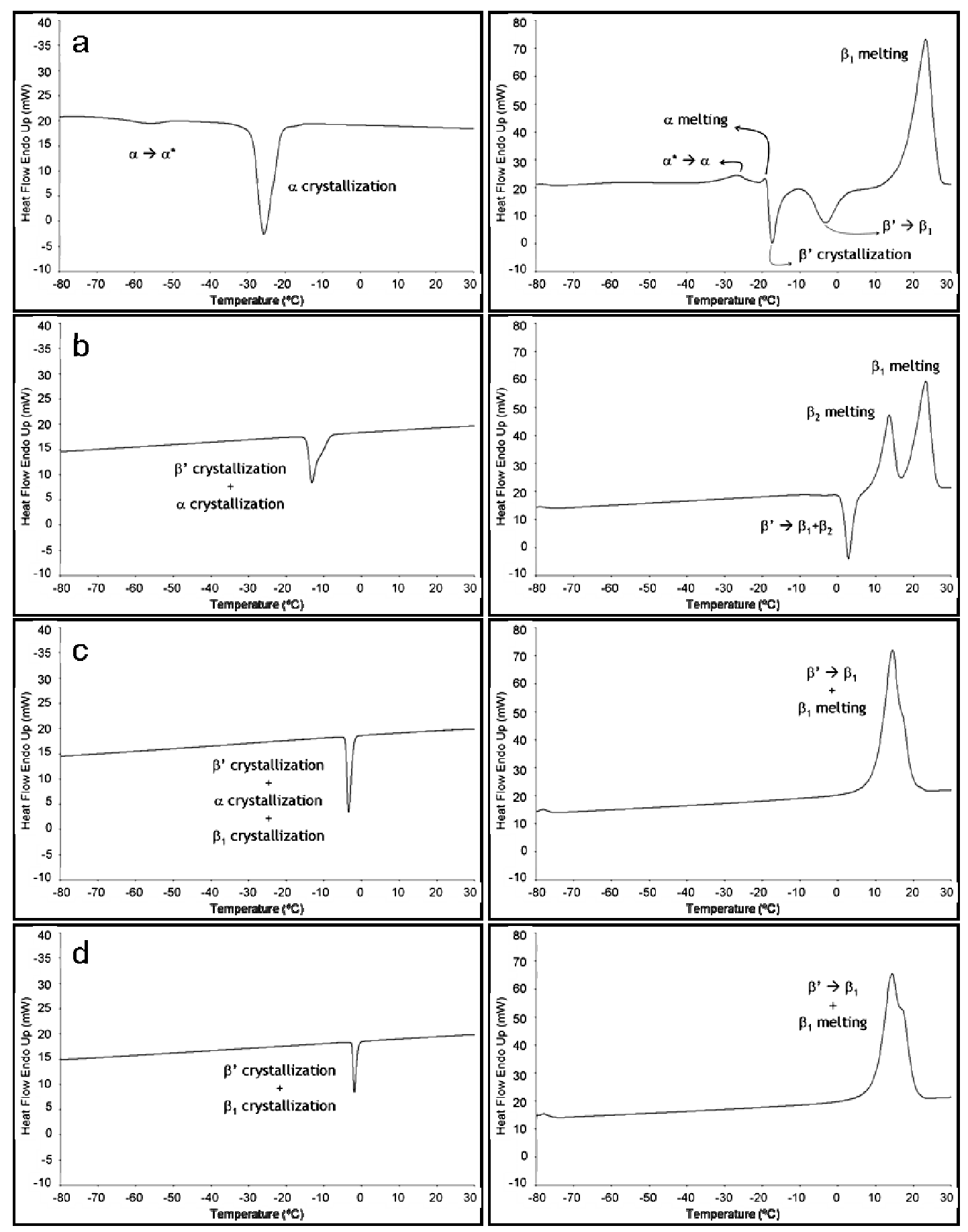

Figure 1. DSC thermograms of OPO obtained by changing the cooling rate and keeping a heating rate of $15^{\circ} \mathrm{C} \cdot \mathrm{min}^{-1}$. a) Cooling profile at a rate of $15^{\circ}$ $\mathrm{C} \cdot \mathrm{min}^{-1}$ and heating profile; b) Cooling profile at a rate of $2^{\circ} \mathrm{C} \cdot \mathrm{min}^{-1}$ and heating profile; c) Cooling profile at a rate of $1^{\circ} \mathrm{C} \cdot \mathrm{min}^{-1}$ and heating profile; d) Cooling profile at a rate of $0.5^{\circ} \mathrm{C} \cdot \mathrm{min}^{-1}$ and heating profile.

kinetic properties regarding to the crystallization rates of four forms of OPO at different cooling rates were not studied. The present work is focused on the influence of a kinetic parameter (cooling rate) on the polymorphic crystallization of ${ }_{10}(\mathrm{OPO})$. In particular, the relationship between this behavior and the Ostwald step rule is examined.

Synchrotron Radiation X-Ray Diffraction (SR-XRD) has been applied to the polymorphic transformations of TAGs. ${ }^{17,} 31,32$ Using this technique and Differential Scanning Calorimetry 15 (DSC) enables rapid thermal programs to provide highly accurate structural information. However, few studies using SR-XRD have been conducted to determine the relative occurrence of the polymorphic forms of TAGs, since most work has been performed with an optical microscope, DSC, 
Table 1. $T_{\text {onset }}$ for each transition, obtained from the DSC data for OPO when the sample is cooled down at different cooling rates and heated at $15^{\circ} \mathrm{C} \cdot \mathrm{min}^{-1}$

\begin{tabular}{|c|c|c|c|c|c|c|}
\hline \multicolumn{2}{|c|}{ COOLING (rate: $15^{\circ} \mathrm{C} \cdot \mathrm{min}^{-1}$ ) } & \multicolumn{5}{|c|}{ HEATING $\left(\right.$ rate: $\left.15^{\circ} \mathrm{C} \cdot \mathrm{min}^{-1}\right)$} \\
\hline$\alpha$ crystallization & $\alpha \rightarrow \alpha^{*}$ transition & $\alpha * \rightarrow \alpha$ transition & $\alpha$ melting & $\beta^{\prime}$ crystallization & $\beta^{\prime} \rightarrow \beta_{1}$ transition & $\beta_{1}$ melting \\
\hline $\mathrm{T}_{\text {onset }}\left({ }^{\circ} \mathrm{C}\right)$ & $\mathrm{T}_{\text {onset }}\left({ }^{\circ} \mathrm{C}\right)$ & $\mathrm{T}_{\text {onset }}\left({ }^{\circ} \mathrm{C}\right)$ & $\mathrm{T}_{\text {onset }}\left({ }^{\circ} \mathrm{C}\right)$ & $\mathrm{T}_{\text {onset }}\left({ }^{\circ} \mathrm{C}\right)$ & $\mathrm{T}_{\text {onset }}\left({ }^{\circ} \mathrm{C}\right)$ & $\mathrm{T}_{\text {onset }}\left({ }^{\circ} \mathrm{C}\right)$ \\
\hline$-21.7 \pm 0.3$ & $-50.8 \pm 1.6$ & $-37.3 \pm 0.4$ & $-21.5 \pm 0.3$ & $-20.1 \pm 0.3$ & $-9.5 \pm 0.3$ & $13.6 \pm 0.6$ \\
\hline \multicolumn{2}{|c|}{ COOLING $\left(\right.$ rate: $\left.2^{\circ} \mathrm{C} \cdot \mathrm{min}^{-1}\right)$} & \multicolumn{4}{|c|}{ HEATING (rate: $15^{\circ} \mathrm{C} \cdot \mathrm{min}^{-1}$ ) } & \\
\hline \multicolumn{2}{|c|}{ Crystallization } & \multicolumn{2}{|c|}{$\beta^{\prime} \rightarrow \beta_{1}+\beta_{2}$ transition } & $\beta_{2}$ melting & $\beta_{1}$ melting & \\
\hline $\mathrm{T}^{\prime}{ }_{\text {onset }}\left({ }^{\circ} \mathrm{C}\right)$ & $\mathrm{T}_{\text {onset }}\left({ }^{\circ} \mathrm{C}\right)$ & \multicolumn{2}{|c|}{$\mathrm{T}_{\text {onset }}\left({ }^{\circ} \mathrm{C}\right)$} & $\mathrm{T}_{\text {onset }}\left({ }^{\circ} \mathrm{C}\right)$ & $\mathrm{T}_{\text {onset }}\left({ }^{\circ} \mathrm{C}\right)$ & \\
\hline$-7.6 \pm 0.5$ & $-10.4 \pm 0.7$ & \multicolumn{2}{|c|}{$-0.4 \pm 0.3$} & $6.9 \pm 1$ & $15.8 \pm 0.7$ & \\
\hline \multicolumn{2}{|c|}{ COOLING $\left(\right.$ rate: $\left.1^{\circ} \mathrm{C} \cdot \mathrm{min}^{-1}\right)$} & \multirow{2}{*}{\multicolumn{2}{|c|}{$\begin{array}{l}\text { HEATING } \quad\left(\text { rate: } 15^{\circ} \mathrm{C} \cdot \mathrm{min}^{-1}\right) \\
\beta^{\prime} \rightarrow \beta_{1} \text { transition and } \beta_{1} \text { melting }\end{array}$}} & & & \\
\hline \multicolumn{2}{|c|}{ Crystallization } & & & & & \\
\hline \multicolumn{2}{|c|}{$\mathrm{T}_{\text {onset }}\left({ }^{\circ} \mathrm{C}\right)$} & \multicolumn{2}{|c|}{$\mathrm{T}_{\text {onset }}\left({ }^{\circ} \mathrm{C}\right)$} & & & \\
\hline \multicolumn{2}{|c|}{$-1.6 \pm 0.6$} & \multicolumn{2}{|c|}{$7.2 \pm 0.7$} & & & \\
\hline \multicolumn{2}{|c|}{ COOLING (rate: $0.5^{\circ} \mathrm{C} \cdot \mathrm{min}^{-1}$ ) } & \multicolumn{2}{|c|}{ HEATING $\left(\right.$ rate: $\left.15^{\circ} \mathrm{C} \cdot \mathrm{min}^{-1}\right)$} & & & \\
\hline \multicolumn{2}{|c|}{ Crystallization } & \multicolumn{2}{|c|}{$\beta^{\prime} \rightarrow \beta_{1}$ transition and $\beta_{1}$ melting } & & & \\
\hline \multicolumn{2}{|c|}{$\mathrm{T}_{\text {onset }}\left({ }^{\circ} \mathrm{C}\right)$} & \multicolumn{2}{|c|}{$\mathrm{T}_{\text {onset }}\left({ }^{\circ} \mathrm{C}\right)$} & & & \\
\hline \multicolumn{2}{|c|}{$-0.4 \pm 0.5$} & \multicolumn{2}{|c|}{$6.9 \pm 0.4$} & & & \\
\hline
\end{tabular}



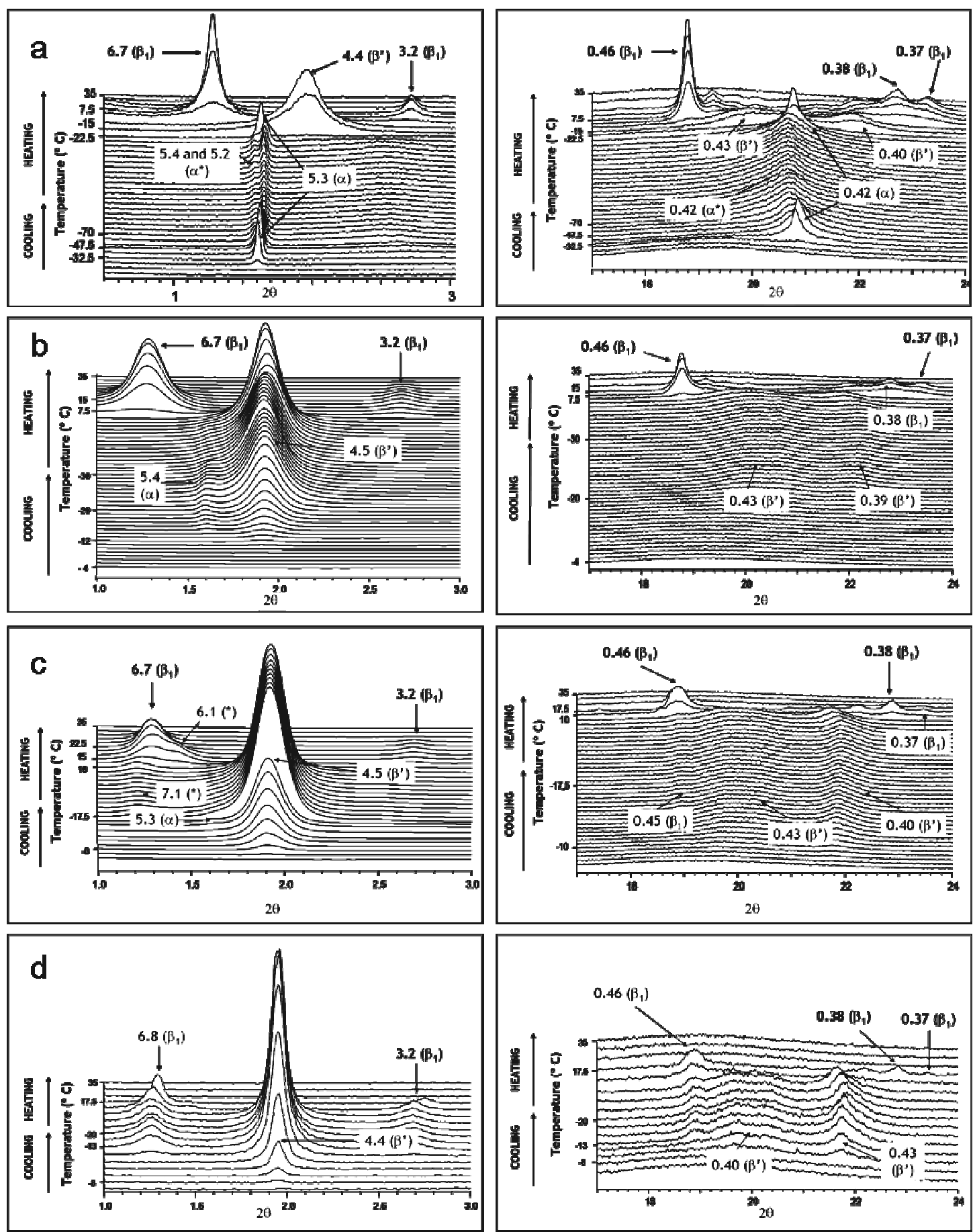

Figure 2. SR-XRD SAXD (left) and WAXD (right) patterns of OPO corresponding to the respective DSC programs. d-spacing values (nm) are shown for the most representative peaks. a) Cooling rate: $15^{\circ} \mathrm{C} \cdot \mathrm{min}^{-1}$; b) Cooling rate: $2^{\circ} \mathrm{C} \cdot \mathrm{min}^{-1}:(*)$ Long spacing values for some intermediate forms; c) Cooling rate: $\left.1^{\circ} \mathrm{C} \cdot \mathrm{min}^{-1} ; \mathrm{d}\right)$ Cooling rate: $0.5^{\circ} \mathrm{C} \cdot \mathrm{min}^{-1}$.

and ex-situ (not on-line) XRD measurements with laboratory equipment after crystallization ceased. SR-XRD can facilitate fast cooling rate measurements because of its high-intensity $\mathrm{X}$-ray beam; thus, it is interesting and valuable to examine the 10 polymorphic crystallization of multiple forms of OPO.

This study characterized the polymorphic crystallization behavior of OPO by DSC, Thermo-optical Microscopy (TOM) and SR-XRD as a function of kinetics (variation of the cooling rates). 15

\section{Experimental}

The 1,3-dioleoyl-2-palmitoyl glycerol (OPO) used for thermal analysis (DSC and TOM) (99\% pure without further purification) was purchased from Larodan Fine Chemicals 

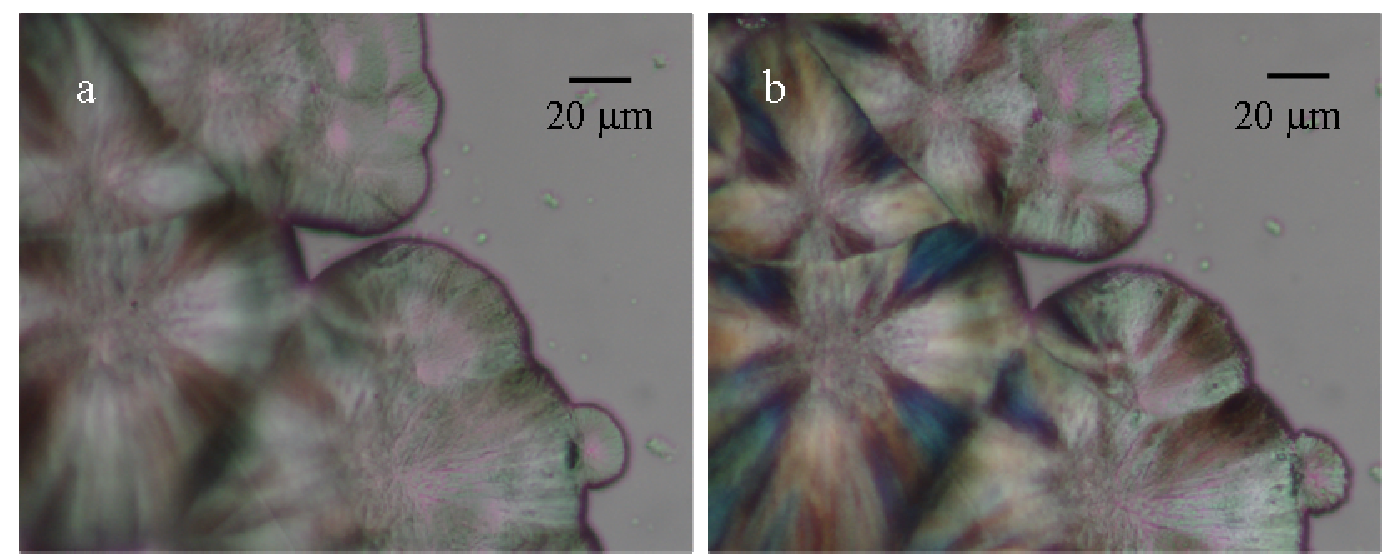

Figure 3. Thermo-optical polarized microscopy images obtained when $\mathrm{OPO}$ was cooled down at $2^{\circ} \mathrm{C} \cdot \mathrm{min}^{-1}$ and heated at $15^{\circ} \mathrm{C} \cdot \mathrm{min}^{-1}$. The temperature range corresponds to the $\beta^{\prime} \rightarrow \beta_{1}+\beta_{2}$ phase transition. The colour changes become clearly noticeable. a) $-14.3^{\circ} \mathrm{C}$; b) $4.5^{\circ} \mathrm{C}$.

(Malmö, Sweden). The 1,3-dioleoyl-2-palmitoyl glycerol used 5 for SR-XRD was also $99 \%$ pure and it was obtained from Tsukishima Foods Industry (Tokyo, Japan). The DSC profiles for both compounds were completely identical.

DSC was performed at atmospheric pressure using a PerkinElmer DSC-7 calorimeter. Samples (9.0 to $9.4 \mathrm{mg}$ ) were 10 weighed into $50 \mu \mathrm{l}$ aluminum pans, and covers were sealed into place. The instrument was calibrated by reference to the enthalpy and melting point of indium (melting temperature: $156.6^{\circ} \mathrm{C} ; \Delta \mathrm{H}_{\mathrm{f}}: 28.45 \mathrm{~J} \cdot \mathrm{g}^{-1}$ ) and decane (melting temperature: $29.7^{\circ} \mathrm{C} ; \Delta \mathrm{H}_{\mathrm{f}}: 202.1 \mathrm{~J} \cdot \mathrm{g}^{-1}$ ) standards. An empty pan was used as 15 reference. Dry nitrogen was used as the purge gas in the DSC cell at $23 \mathrm{~cm}^{3} \cdot \mathrm{min}^{-1}$. Thermograms were analyzed with Pyris Series Software to obtain enthalpy $\left(\mathrm{J} \cdot \mathrm{g}^{-1}\right)$ (integration of the DSC signals), $\mathrm{T}_{\text {onset }}\left({ }^{\circ} \mathrm{C}\right)$, and $\mathrm{T}_{\text {end }}\left({ }^{\circ} \mathrm{C}\right)$ of the transitions (intersection of the baseline and the initial and final tangent at 20 the transition).

Samples were cooled at different cooling rates $\left(15^{\circ} \mathrm{C} \cdot \mathrm{min}^{-1}\right.$, $2^{\circ} \mathrm{C} \cdot \mathrm{min}^{-1}, 1^{\circ} \mathrm{C} \cdot \mathrm{min}^{-1}$ and $0.5^{\circ} \mathrm{C} \cdot \mathrm{min}^{-1}$ ) from $35^{\circ} \mathrm{C}$ to $-80^{\circ} \mathrm{C}$ and heated at $15^{\circ} \mathrm{C} \cdot \mathrm{min}^{-1}$. A minimum of three independent measurements was made for each experiment $(n=3)$. Random 25 uncertainty was estimated with a $95 \%$ threshold of reliability using the Student's Method, which enables estimating the mean of a normally distributed population when the population is small. For analysis that did not take place at a rate of $2^{\circ} \mathrm{C} \cdot \mathrm{min}^{-1}$, a correction had to be made, as the DSC-7 30 was calibrated at the before-mentioned rate. The following expression was applied at each value: ${ }^{33}$

$$
T_{\text {true }}=T_{o b s}-C \cdot(d T / d t)_{a}+C \cdot(d T / d t)_{b}
$$

35 where $\mathrm{C}$ is a constant value $(0.085),(\mathrm{dT} / \mathrm{dt})_{\mathrm{a}}$ is the rate of the analysis, and $(\mathrm{dT} / \mathrm{dt})_{\mathrm{b}}$ is the calibration rate $\left(2^{\circ} \mathrm{C} \cdot \mathrm{min}^{-1}\right)$.

TOM images were obtained on a Linkam THMSG-600 stage mounted to a Nikon Eclipse 50iPol Microscope. The sample was placed on a $7 \mathrm{~mm}$ quartz cover slip and encased within a ${ }_{40}$ pure Ag lid to ensure a uniform temperature. An LNP liquid nitrogen cooling system and a TMS94 temperature controller were used. Images were captured with a Nikon Digital Camera DXM1200F and NIS-Elements Software.

SR-XRD experiments were carried out at two different
45 beamlines (BL-15A and BL-9C) of the SR source Photon Factory (PF) in the National Laboratory for High-Energy Physics (Tsukuba, Japan). For both beamlines, a doublefocusing camera operated at a wavelength $0.15 \mathrm{~nm}$. For BL9C, the X-Ray scattering data were detected by Position 50 Sensitive Proportional Counters (PSPCs) for the small (SAXD) and wide angles (WAXD) simultaneously. For BL15A, two different detectors were used: a CCD camera for small-angle data and PSPC for wide-angle data. The SAXD and WAXD measurements were simultaneous. The SAXD 55 pattern was used for determining the chain length structure of the triacylglycerol and the WAXD pattern permitted us to identify the polymorphic forms ${ }^{34}$. The temperature program applied to the sample was controlled by a Mettler DSC-FP84 (Mettler Instrument Corp., Greifensee, Switzerland) with ${ }_{60}$ FP99 software. A $2 \mathrm{~mm}$-thick sample was placed in a stainless steel sample cell with Kapton film windows. It should be noted that the SR-XRD spectra were taken at $30 \mathrm{~s}$ or $60 \mathrm{~s}$ intervals, depending on the cooling rate and the number of transitions observed in the DSC profile. 65

\section{Results and discussion}

Figure 1 depicts the OPO DSC thermograms (cooling and heating) obtained by changing the cooling rate and keeping the same heating rate of $15^{\circ} \mathrm{C} \cdot \mathrm{min}^{-1}$. Table 1 specifies $T_{\text {onset }}$ 70 for each transition. Crystal forms were identified by the SRXRD patterns of simultaneous SAXD and WAXD measurements following the same DSC programs (Fig. 2). Long spacing values of $\alpha, \beta^{\prime}, \beta_{1}$, and $\beta_{2}$ forms are known from the work of Minato et al. ${ }^{12}$

${ }_{75}$ Cooling rate: $1^{\circ} \mathbf{C} \cdot \mathbf{m i n}^{-1}$. On cooling, the polymorphic form that crystallizes is $\alpha$ (less stable). Afterwards, a solid-solid transition takes place at $-50.8 \pm 1.6^{\circ} \mathrm{C}$ (Table 1) to obtain another $\alpha$ form $\left(\alpha^{*}\right)$, characterized by an appreciable double peak in the SAXD pattern (5.4 and $5.2 \mathrm{~nm})$ and a broad peak in 80 the WAXD pattern $(0.42 \mathrm{~nm})$. Ueno et al. ${ }^{32}$ reported an $\alpha$ form for SOS, characterized by a double peak in the SAXD pattern and they explained the transformation from the double SAXD peak into a single peak (characteristic of $\alpha$ ) as a relaxation process of the $\alpha$ form. In the present work, we have called this 
Table 2. Crystallographic data of the OPO polymorphic forms.

\begin{tabular}{|c|c|c|c|c|c|c|c|}
\hline & \multicolumn{4}{|c|}{ Present work } & \multicolumn{3}{|c|}{ Minato et al. work ${ }^{12}$} \\
\hline & $\alpha$ & $\alpha^{*}$ & $\beta$, & $\beta_{1}$ & $\alpha$ & $\beta$, & $\beta_{1}$ \\
\hline $\begin{array}{l}\text { Short Spacing } \\
(\mathrm{nm})\end{array}$ & 0.42 & 0.42 & $\begin{array}{l}0.43 \\
0.40\end{array}$ & $\begin{array}{l}0.46 \\
0.38 \\
0.37\end{array}$ & ---- & ---- & ---- \\
\hline $\begin{array}{l}\text { Long Spacing } \\
\qquad(\mathrm{nm})\end{array}$ & 5.3 & $\begin{array}{l}5.4 \\
5.2\end{array}$ & 4.4 & 6.7 & 4.8 & 4.4 & 6.4 \\
\hline $\begin{array}{l}\text { Chain Length } \\
\text { Structure }\end{array}$ & Double & Double & Double & Triple & Double & Double & Triple \\
\hline
\end{tabular}

form, characterized by the double SAXD peak, $\alpha^{*}$.

During the heating process, the $\alpha *$ form transforms into $\alpha$ and 5 melts. $\beta$ ' then crystallizes (identified by two peaks in the WAXD pattern, with d-spacings of 0.43 and $0.40 \mathrm{~nm}$ ) and is transformed into the $\beta_{1}$ form (exothermic transition, see Fig. $1)$. Finally, the $\beta_{1}$ form, which is the most stable one, melts. These results are in agreement with the work of Minato et 10 al., ${ }^{12}$ who studied the polymorphism of POP:OPO binary mixtures and observed the same behavior for pure OPO.

Cooling rate: $\mathbf{2}^{\circ} \mathbf{C} \cdot \mathbf{m i n}^{-1}$. In the SAXD pattern, concurrent crystallization of $\alpha$ and $\beta$ ' forms is observed. However, on heating, the intensity of $\alpha$ peaks decreases, while that of $\beta$ ' 15 peaks increases, possibly due to an $\alpha \rightarrow \beta^{\prime}$ transition. Nevertheless, in the WAXD pattern, only $\beta$ ' crystallization is clearly noticeable. However, the first $\beta^{\prime}$ peak $(0.43 \mathrm{~nm})$ is broader than when the cooling rate is $15^{\circ} \mathrm{C} \cdot \mathrm{min}^{-1}$, possibly due to an overlapping of the $\beta^{\prime}$ first peak and a smooth $\alpha$ peak.

20 According to the DSC thermogram, on heating, a transition from $\beta$ ' to $\beta_{1}$ and $\beta_{2}$ must take place simultaneously, as two melting endothermic peaks are present. Nevertheless, in both the SAXD and the WAXD patterns, only the $\beta_{1}$ polymorphic form could be observed.

${ }_{25}$ Figure 3 illustrates a thermo-optical polarized microscopy experiment using the same DSC program. In the temperature range of the solid-solid transition $\beta^{\prime} \rightarrow \beta_{1}+\beta_{2}$, the sample, crystallized as spherulites, exhibited clear color changes, due to the solid-solid transition: before the transition it is possible

30 to appreciate some brown and green colors (Figure 3a) and there are some changes to obtain some blue, yellow and brown tonalities (Figure 3b). However, it is not possible to distinguish between the newly formed $\beta_{1}$ and $\beta_{2}$ forms using this technique.

${ }_{35}$ Cooling rate: $\mathbf{1}^{\mathbf{0}} \mathbf{C} \cdot \mathbf{m i n}^{-1}$. On the one hand, the SAXD pattern exhibits concurrent crystallization of $\alpha$ and $\beta$ ' forms in the cooling process, although the $\alpha$ peak does not become important and disappears immediately. On the other hand, the crystallization of $\beta^{\prime}$ is also present in the WAXD pattern, but 40 is accompanied by some $\beta_{1}$ crystallization. Therefore, both SAXD and WAXD results indicate concurrent crystallization of $\alpha, \beta$, and $\beta_{1}$ forms.

When the sample is heated, all $\beta$ ' is transformed into $\beta_{1}$, but before this transition, some peaks of possible intermediate

45 forms can be seen in the SAXD profile $(7.1$ and $6.1 \mathrm{~nm})$. We must point out that only one endothermic peak with a shoulder is observed in the DSC heating thermogram, whereas the $\beta$, $\rightarrow \beta_{1}$ transition should be exothermic. This may be because the $\beta_{1}$ melting process becomes so energetic that the 50 convolution of both phenomena $\left(\beta^{\prime} \rightarrow \beta_{1}\right.$ transition and $\beta_{1}$ melting) becomes a single endothermic peak in the DSC.

Cooling rate: $\mathbf{0 . 5}^{\circ} \mathbf{C} \cdot \mathbf{m i n}^{-1}$. According to the SAXD and WAXD patterns, $\alpha$ does not crystallize when cooling, and there is only a concurrent crystallization of $\beta^{\prime}$ and $\beta_{1}$. ${ }_{55}$ Afterwards, $\beta$ ' transforms into $\beta_{1}$ on heating and $\beta_{1}$ melts. The DSC obtained is similar to the previous one.

In order to check the crystallization behavior at an intermediate cooling rate between 15 and $2^{\circ} \mathrm{C} \cdot \mathrm{min}^{-1}$, DSC experiments at a cooling rate of $8^{\circ} \mathrm{C} \cdot \mathrm{min}^{-1}$ and heating rate of ${ }_{60} 15^{\circ} \mathrm{C} \cdot \mathrm{min}^{-1}$ were carried out (not shown). The thermal profiles were similar to the one obtained by the cooling at $2^{\circ} \mathrm{C} \cdot \mathrm{min}^{-1}$ whose details are explained in Figure $1 \mathrm{~b}$.

Overall, as the cooling rate decreases, the DSC profiles become simpler. This fact is represented in the triangular 65 shape of Table 1. Also, $T_{\text {end }}$ and enthalpy values were determined for each transition, and some comparisons can be established. When the cooling rate is $15^{\circ} \mathrm{C} \cdot \mathrm{min}^{-1}, \alpha$ form crystallizes, giving an energetic peak; however, the $\alpha \rightarrow \alpha^{*}$ transition is less energetic and much broader. Afterwards, the 70 energy of the $\alpha$ melting is low when heating, and the correspondent peak becomes very narrow. The energy for the following $\beta^{\prime}$ crystallization and $\beta^{\prime} \rightarrow \beta_{1}$ transition are about the same magnitude as for the $\alpha$ crystallization. Finally, the $\beta_{1}$ melting is more energetic than all the previous phenomena, 75 and the peaks become broader than that of the $\alpha$ crystallization. With cooling rates of $2^{\circ}, 1^{\circ}$, and $0.5^{\circ} \mathrm{C} \cdot \mathrm{min}^{-1}$, concurrent crystallizations take place, so the processes are more complex and energies are higher $\left(100 \mathrm{~J} \cdot \mathrm{g}^{-1}\right)$, due to the overlapping of some phenomena, although the correspondent 80 peaks are not so broad. The same happens during the heating step with 1 and $0.5^{\circ} \mathrm{C} \cdot \mathrm{min}^{-1}$ : as the endothermic peak is, in fact, a convolution of the $\beta^{\prime} \rightarrow \beta_{1}$ transition and the $\beta_{1}$ melting, and energies become high. When the cooling rate is $2^{\circ} \mathrm{C} \cdot \mathrm{min}^{-}$ ${ }^{1}$, the energy value for the transition $\beta^{\prime} \rightarrow \beta_{1}+\beta_{2}$ (heating 85 step) is similar to that for the $\beta^{\prime} \rightarrow \beta_{1}$ transition with a cooling rate of $15^{\circ} \mathrm{C} \cdot \mathrm{min}^{-1}$. Comparison of the two experiments also indicates that the energy value of the convolution of $\beta_{1}$ and $\beta_{2}$ melting (it was not possible to separate the two peaks) is the same as for $\beta_{1}$ melting. Therefore, it can be concluded that $\beta_{2}$ 90 crystallization and melting are not as energetic as that of $\beta_{1}$, and the amount of $\beta_{2}$ crystallized is not as high. The $T_{\text {onset }}$ of $\beta_{1}$ melting when the cooling rates are $15^{\circ}$ and $2^{\circ} \mathrm{C} \cdot \mathrm{min}^{-1}$ are 


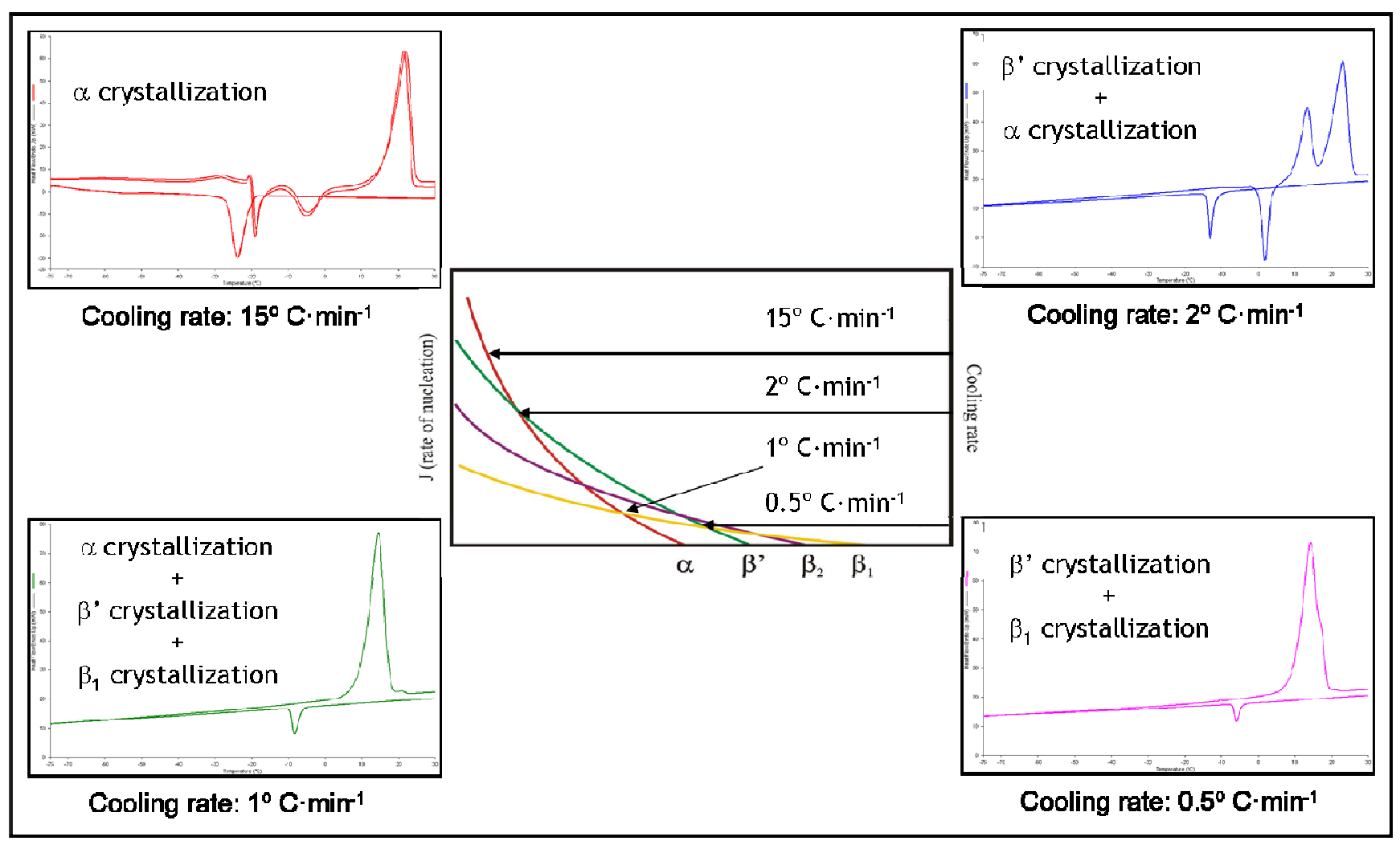

Figure 4. Diagram of the influence of changing the cooling rate on the OPO polymorphism.

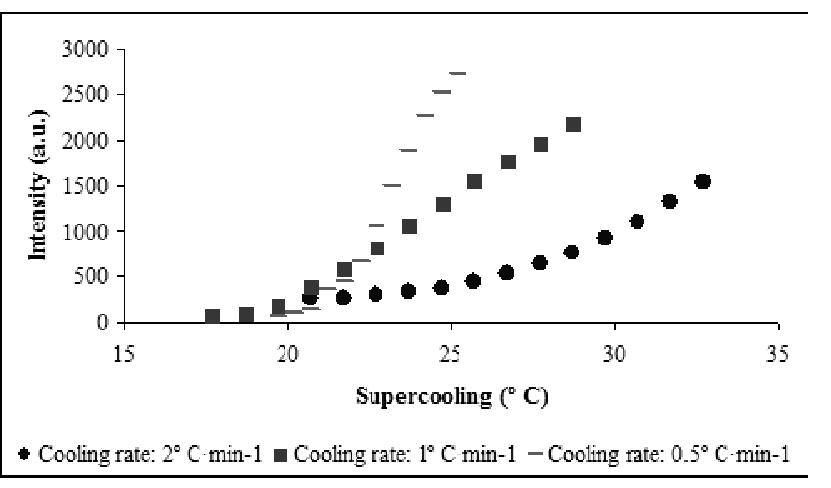

5 Figure 5. Graphs showing the relation cooling rate-crystallization rate for $\beta$ '

slightly different due to the fact that, at $2^{\circ} \mathrm{C} \cdot \mathrm{min}^{-1}$, the $\beta_{1}$ melting peak is close to the $\beta_{2}$ melting peak, so the $\beta_{2}$ melting process makes some influence to change somehow the $\beta_{1}$ 10 melting value. However, at $15^{\circ} \mathrm{C} \cdot \mathrm{min}^{-1}$, the $\beta_{1}$ melting peak is completely isolated.

All the crystallographic data obtained in order to characterize each polymorph are summarized in Table 2, where a comparison with the Minato et al. ${ }^{12}$ results can also be found. ${ }_{15}$ We have defined the chain length structure of $\alpha$ and $\alpha *$ as double, although the long spacing values are higher (from 5.2 to 5.4) than those of Minato et al. As other studies have confirmed, ${ }^{32}$ sometimes $\alpha$ form can reach these high values, which can be understood as a more straight double chain 20 structure.
According to the Ostwald step rule for polymorphic nucleation, the solid first formed on crystallization of a melt or a solution would be the least stable polymorph, which is first produced by spontaneous crystallization. As Ostwald 25 stated: "When leaving a given state and in transforming to another state, the state which is sought out is not the thermodynamically stable one, but the nearest in stability to the original state" and this must be the next least stable (the one with the smallest energy barrier expressed in 30 kinetic/thermodynamic terms) ${ }^{4}$. However, some factors (e.g., cooling rate) affect crystallization ${ }^{26,27}$ and polymorphic nucleation. In this work, we have shown the influence of kinetics, so that as the cooling rate decreases, more stable forms crystallize, not following the Ostwald step rule. In most 35 cases, concurrent crystallizations of different polymorphs occur, but the tendency becomes clear. Therefore, this becomes an example where kinetics, thermodynamics and structural factors are competing. However, the Ostwald's Rule also states that the polymorph first formed is followed 40 successively by forms of increasing stability. This fact has been observed on the heating profiles of the experiments performed in the present work, as the phase transitions follow a sequence by continuously increasing the stability of the forms obtained. Nevertheless, further work would be required 45 to determine the effects of changing heating rates on polymorphism. Figure 4 summarizes the influence of cooling rate variation on the OPO polymorphism. The proposed diagram includes all the polymorphic sequences experimentally observed. As DSCs show, a more simplified ${ }_{50}$ polymorphic behavior is obtained with a decreased cooling 
rate because the transformation sequence becomes shorter. Moreover, we studied the relation between the cooling and the crystallization rates of the $\beta$ ' form (Fig. 5). The variation of the SAXD peaks intensity of $\beta$ ' (at 4.5 or $4.4 \mathrm{~nm}$ ), present 5 during the cooling process (at three rates of cooling), is represented in front of the supercooling $\left(\Delta \mathrm{T}=\mathrm{T}_{\mathrm{m}}-\mathrm{T}_{\mathrm{c}}\right)$, in which $T_{m}$ is the melting temperature of $\beta$, form and $T_{c}$ becomes each experimental temperature. It was evident that the SAXD peak intensity increased more rapidly as the 10 cooling rate decreased above the $\Delta \mathrm{T}$ values of $22^{\circ} \mathrm{C}$. Although the degree of perfection of crystals or crystallinity may vary the corresponding XRD peaks in that less perfect crystal diffract less X-ray beams, the intensity of the XRD peaks basically depends on the concentration of crystals present in 15 the growth medium that were subjected to XRD measurement. Therefore, the results (Fig. 5) may be related to the amount of $\beta$ ' crystals formed during different rates of cooling. It appeared that the rate of crystallization decreased with increasing cooling rate, since the peak intensity of the SAXD ${ }_{20}$ pattern decreased with increasing $\Delta \mathrm{T}$ and cooling rate. However, this was not the case. The amount of crystals is the summation of the crystallized materials in the supercooled liquid, resulting from both the rate of nucleation and subsequent crystal growth. The rate of nucleation is defined

25 as the increase in crystal numbers per unit of time and unit of volume of supercooled liquid, and the rate of crystal growth is defined as the increase in volume of crystals per unit time. As the rate of cooling decreases, the amount of time required for the growth medium to allow crystal nucleation and crystal 30 growth to occur increases; therefore, the integrated amount of crystals may increase with time. This phenomenon was clearly observed for the same polymorphic form of $\beta$ ' as depicted in Fig. 5. For example, at a supercooling value of 24 ${ }^{\circ} \mathrm{C}$, the intensity values of XRD peaks obtained at the cooling 35 rates of $2{ }^{\circ} \mathrm{C} / \mathrm{min}, 1{ }^{\circ} \mathrm{C} / \mathrm{min}$ and $0.5{ }^{\circ} \mathrm{C} / \mathrm{min}$ are 335,1065 and 1900, respectively. Then the times allocated for crystallization during supercooled conditions are 12 minutes $\left(2{ }^{\circ} \mathrm{C} / \mathrm{min}\right), 24$ minutes $\left(1{ }^{\circ} \mathrm{C} / \mathrm{min}\right)$ and 48 minutes $(0.5$ $\left.{ }^{\circ} \mathrm{C} / \mathrm{min}\right)$. This result qualitatively shows the dependence of 40 the cooling rate on the extent of crystallization due to the difference in crystallization time.

\section{Conclusions}

DSC and SR-XRD clarified the polymorphic behavior of OPO as a function of kinetics. As the cooling rate decreases, the 45 polymorphic crystallization is directed to more stable forms, not following the Ostwald step rule. Nevertheless, concurrent crystallization often occurs in a complex phenomena. In more detail, when the cooling rate was $15^{\circ} \mathrm{C} \cdot \mathrm{min}^{-1}, \alpha$ form crystallized; at $2^{\circ} \mathrm{C} \cdot \mathrm{min}^{-1}, \alpha$ and $\beta$, formed; at $1^{\circ} \mathrm{C} \cdot \mathrm{min}^{-1}$ ${ }_{50}$ concurrent crystallization of $\alpha, \beta^{\prime}$ and $\beta_{1}$ occurred; and when the controlled cooling rate was $0.5^{\circ} \mathrm{C} \cdot \mathrm{min}^{-1}, \beta^{\prime}$ and $\beta_{1}$ crystallized. Using SR-XRD coupled with DSC, rapid dynamic polymorphic transformations on the heating step could be identified. Also, intensities of the SAXD peaks have ${ }_{55}$ been related to supercooling for $\beta$ ' form, by comparing the slopes of the graphs obtained at each cooling rate. Results indicate that the nucleation rate of $\beta$ ' tends to increase as the cooling rate decreases.

\section{Acknowledgements}

${ }_{60}$ The authors acknowledge the financial support of the Ministerio de Ciencia y Tecnología through the CICYT (Project MAT2008-00497/NAN), the Generalitat de Catalunya through the Grup Consolidat (SGR 2009 1307) and the Ministerio de Educación through la Factoría Cristalográfica 65 (Consolider-Ingenio, CSD2006-15) and through a Beca del Programa de Formación del Profesorado Universitario (FPU).

\section{Notes and references}

a. Departament de Cristal-lografia, Mineralogia i Dipòsits Minerals, Facultat de Geologia, Universitat de Barcelona, Martí i Franquès s/n, E70 08028 Barcelona, Spain. FAX: (+34) 934021340; TEL: (+34)

934021350; E-mail: laurabayes@ub.edu

b. Graduate School of Biosphere Science, Hiroshima University, HigashiHiroshima 739, Japan.

1 J. Bernstein, Polymorphism in Molecular Crystals, Oxford University 75 Press, New York, USA, 2002.

2 N. Widlak, R. Hartel and S. Narine, Ed. Crystallization and Solidification Properties of Lipids, AOCS Press, Champaign, USA, 2001; pp 53-131.

3 W. Ostwald, Z. Phys. Chem. 1897, 22, 289.

804 T. Threlfall, Org. Process Res. Dev. 2003, 7, 1017.

5 D. Aquilano and G. Sgualdino, In Crystallization Processes in Fats and Lipid Systems; N. Garti and K. Sato, Ed.; Marcel Dekker, New York, USA, 2001; pp 1-51.

6 T. Aree, N. Chaichit and C. Engkakul, Carbohyd. Res. 2008, 343 2451.

7 D. Zhao, Y. Zhu, Q. Ruan, S. Zhang, L. Zhang, and F. Xu, Mater. Res. Bull. 2010, 45, 80.

8 G. Falini, S. Fermani, M. Gazzano and A. Ripamonti, A. Chem. Eur. J. 1998, 4 (6), 1048.

909 A. G. Marangoni and S. S. Narine, Ed. Physical Properties of Lipids; Marcel Dekker, New York, USA, 2002; pp 63-217.

10 J. M. deMan, In Physical Properties of Fats, Oils and Emulsifiers; Widlak, N., Ed.; American Oils Chemists' Society Press, Champaign, IL, 2000; pp 79-95.

9511 K. Sato and S. Ueno, In Crystallization Processes in Fats and Lipid Systems; N. Garti and K. Sato, Ed.; Marcel Dekker, New York, USA, 2001; pp 177-209.

12 A. Minato, S. Ueno, J. Yano, K. Smith, H. Seto, Y. Amemiya and K. Sato, JAOCS. 1997, 74 (10), 1213

10013 C. Akita, T. Kawaguchi and F. Kaneko, J. Phys. Chem. B. 2006, 110 (9), 4346.

14 K. Sato, T. Arishima, Z. H. Wang, K. Ojima, N. Sagi and H. Mori, JAOCS. 1989, 66, 664.

15 J. Yano, K. Sato, F. Kaneko, D. M. Small and D. R. Kodali, J. Lipid Res. 1999, 40, 140.

16 L. Zhang, S. Ueno, S. Miura and K. Sato, J. Amer. Oil Chem. Soc. $2007,84,219$.

17 A. Minato, S. Ueno, K. Smith, Y. Amemiya and K. Sato, J. Phys. Chem. B. 1997, 101 (18), 3498.

1018 K. Sato, S. Ueno and J. Yano, Prog. Lipid Res. 1999, 38, 91.

19 C. Himawan, V. M. Starov and A. G. F. Stapley, Adv. Colloid Interfac. 2006, 122, 3.

20 P. Rousset, M. Rappaz and E. Minner, JAOCS. 1998, 75 (7), 857.

21 T. Koyano, I. Hachiya, T. Arishima, N. Sagi and K. Sato, J. Am. Oil Chem. Soc. 1991, 68, 716 .

22 C. L. Chong, Z. Kamarudin, P. Lesieur, A. Marangoni, C. Bourgaux, M. Ollivon, Eur. J. Lipid Sci. Technol. 2007, 109, 410.

23 C. P. M. Roelands, J. H. ter Horst, H. J. M. Krammer and P. J. Jansens, Cryst. Growth Des. 2006, 6 (6), 1380.

2024 I. Foubert, E. Fredrick, J. Vereecken, M. Sichien and K. Dewettinck, Termochim. Acta. 2008, 471, 7. 
25 A. G. Marangoni, T. C. Aurand, S. Martini and M. Ollivon, Cryst. Growth Des. 2006, 6 (5), 1199.

26 L. Bouzidi and S. S. Narine, Langmuir. 2009, 26 (6), 4311.

27 R. Lam, L. Quaroni, T. Pederson and M. A. Rogers, Soft Matter. 2010, 6, 404.

28 G. Calliauw, V. Gibon, W. de Greyt, L. Plees, I Foubert and K. Dewettinck, J. Am. Oil Chem. Soc. 2007, 84, 885.

29 R. E. Timms, Eur. J. Lipid Sci. Technol. 2005, 107 (1), 48.

30 K. W. Smith, In Crystallization Processes in Fats and Lipid Systems;

$10 \quad$ N. Garti and K. Sato, Ed.; Marcel Dekker, New York, USA, 2001; pp 357-380.

31 S. Ueno, A. Minato, J. Yano and K. Sato, J. Cryst. Growth. 1999, 198/199, 1326.

32 S. Ueno, A. Minato, H. Seto, Y. Amemiya and K. Sato, J. Phys. Chem. B. 1997, 101, 6847.

33 Instructions Model DSC-4. Perkin Elmer, Norwalk, Connecticut, USA, (1982).

34 C. Lopez, N. Karray, P. Lesieur and M. Ollivon, Eur. J. Lipid Sci. Technol. 2005, 107, 673. 